\title{
COVID-19 Is a Persistent Reallocation Shock
}

\author{
Jose Maria Barrero, ${ }^{*}$ Nicholas Bloom, ${ }^{\dagger}$ Steven J. Davis, ${ }^{\ddagger}$ and Brent H. Meyer ${ }^{\S}$
}

9 March 2021

\begin{abstract}
Drawing on data from the firm-level Survey of Business Uncertainty, we present three pieces of evidence that COVID-19 is a persistent reallocation shock. First, rates of excess job and sales reallocation over 24-month periods have risen sharply since the pandemic struck, especially for sales. We compute these rates by aggregating over monthly firm-level observations that look back 12 months and ahead 12 months. Second, as of December 2020, firm-level forecasts of sales revenue growth over the next year imply a continuation of recent changes, not a reversal. Third, COVID-19 shifted relative employment growth trends in favor of industries with a high capacity of employees to work from home, and against those with a low capacity.
\end{abstract}

Contact: jose.barrero@itam.mx, nbloom@stanford.edu, Steven.Davis@ chicagobooth.edu, Brent.Meyer@atl.frb.org

JEL No. D22, D84, E23, E24, J21, J62, J63

Keywords: COVID-19, reallocation shock, business expectations, working from home, Survey of Business Uncertainty

Acknowledgements: We thank Stanford University, the University of Chicago Booth School of Business, Asociación Mexicana de Cultura A.C., and the Federal Reserve Bank of Atlanta for financial support.

Disclaimer: Any opinions and conclusions expressed herein are those of the authors and do not necessarily represent the views of the Federal Reserve Bank of Atlanta.

\footnotetext{
* Instituto Tecnológico Autónomo de México

${ }^{\dagger}$ Stanford University

* University of Chicago Booth School of Business and Hoover Institution

$\S$ Federal Reserve Bank of Atlanta
} 
COVID-19 and policy responses to the pandemic have generated massive shifts in demand across businesses and industries. Barrero, Bloom, and Davis (forthcoming) provide evidence on the near, medium, and longer-term reallocative effects of these shifts for the US economy based on data as of Summer 2020. Their evidence points to a major upheaval in labor markets (see also Cajner et al., 2020), initially depressed and later heightened business formation rates (see also Haltiwanger, 2020), high expected job and sales reallocation rates in the wake of the pandemic, and a huge shift to working from home (see also Brynjolfsson et al., 2020, Bick et al., 2020, and Ozimek, 2020). The evidence aligns well with reports of strong growth among firms and industries that benefitted from the pandemic - e.g., e-commerce and retail giants like Amazon and Walmart (Bender and Dalton, 2020; Mitchell, 2020) - even as much of the economy faltered. It also underscores the relevance of theoretical analyses that highlight macroeconomic implications of shocks with large, sharply uneven demand and supply effects (e.g., Guerrieri et al., 2020).

In this paper, we draw on firm-level data in the Atlanta Fed/Chicago Booth/Stanford Survey of Business Uncertainty (SBU) to quantify the pace of reallocation across firms before and after the pandemic struck, to investigate what firm-level forecasts in December 2020 say about expected future sales, and to examine how industry-level employment trends relate to the capacity of employees to work from home. The SBU is a monthly panel survey of U.S. business executives that collects data on own-firm past, current, and expected future sales and employment. The Atlanta Fed recruits high-level executives to join the panel and sends them the survey via email, obtaining about 450 responses per month. The survey yields data on realized firm-level employment and sales growth rates over the preceding twelve months and subjective forecast 
distributions over own-firm growth rates at a one-year look-ahead horizon. ${ }^{1}$ See Altig et al. (2020) for more information about the SBU and an analysis of the firm-level forecast properties.

We report three pieces of evidence on the persistent reallocative effects of the COVID-19 shock. First, rates of excess job and sales reallocation over 24-month periods have risen sharply since the pandemic struck, especially for sales. We compute these rates by aggregating over monthly firm-level observations that look back 12 months and ahead 12 months. We focus on rates of "excess" reallocation, which adjust for net changes in aggregate activity. Second, as of December 2020, firm-level forecasts of sales revenue growth over the next year imply a continuation of recent changes, not a reversal. Firms hit most negatively during the pandemic expect (on average) to grow slowly if they grow at all in 2021, and firms hit positively expect to continue growing. Third, our survey data say that COVID-19 shifted relative employment growth trends in favor of industries with a high capacity of employees to work from home, as measured by Dingel and Neiman (2020a), and against industries with a low capacity.

For each firm $i$ in survey month $t$, we compute the firm's realized plus expected employment growth rate over a 24-month period centered on the survey month: $g_{i, t}^{24}=g_{i, t, t-12}+$ $\mathrm{E}_{i, t} g_{i, t, t+12}$, where $\mathrm{E}_{i, t}$ denotes the firm's subjective expectation at $t$. $^{2}$ We then compute the expected excess job reallocation rate in month $t$ as

$$
X_{t}^{24, \mathrm{jobs}}=\sum_{i \in \mathcal{S}_{t}^{-}}\left(\frac{Z_{i t}}{Z_{t}}\right)\left|g_{i, t}^{24}\right|+\sum_{i \in \mathcal{S}_{t}^{+}}\left(\frac{Z_{i t}}{Z_{t}}\right)\left|g_{i, t}^{24}\right|-\left|\sum_{i}\left(\frac{Z_{i t}}{Z_{t}}\right) g_{i, t}^{24}\right|,
$$

where the first term on the right side is the expected gross job destruction rate over the 24 months centered at $t$, the second term is the expected gross job creation rate, and the third term is the

\footnotetext{
${ }^{1}$ More precisely, the look-ahead horizon is twelve months for employment and four quarters for sales revenue.

${ }^{2}$ We measure growth rates as arc-percentage changes, given by $g_{i, t, t-12}=\left(x_{i, t}-x_{i, t-12}\right) /\left(0.5 x_{i, t}+0.5 x_{i, t-12}\right)$, where $x_{i, t}$ is the level of activity (sales or employment) at firm $i$ in month $t$ and analogously for $\mathrm{E}_{i, t} g_{i, t, t+12}$.
} 
absolute value of the expected net growth rate. The factor $\left(z_{i t} / Z_{t}\right)$ is the ratio of firm $i$ 's employment weight $z_{i t}$ to aggregate activity $Z_{t} \cdot{ }^{3}$ The resulting $X_{t}^{24, j o b s}$ statistic quantifies the volume of cross-firm job reallocation in excess of what's required by the aggregate net change. We compute the expected excess sales reallocation rate in the same way. ${ }^{4}$

Figure 1 plots the excess reallocation rates from January 2017 to December 2020 based on 24-month firm-level changes, as described above. The excess sales reallocation measure rises very sharply upon arrival of the COVID-19 shock in March 2020, and it continues on an upward trajectory through the end of 2020. As of December 2020, the centered 24-month expected sales reallocation rate exceeds 12 percent of aggregate sales. The job reallocation measure shows a more modest rise that also continues through the end of 2020. The upward trajectories in both series indicate that the reallocative effects of the pandemic are continuing to unfold and even accelerate. ${ }^{5}$ Since the pandemic had yet to hit by December 2019, the last month covered by our 12-month look-back interval, Figure 1 also suggests that COVID-19 has reinforced firm-level trends that were already underway before the pandemic.

To examine whether firms expect a (perhaps partial) reversal of pandemic-induced shocks to their sales revenues, we now consider how expected future sales growth rates in December 2020 vary by quantiles in the distribution of realized growth rates over the preceding 12 months. Specifically, in each month $t$ starting in September 2016, we compute sales-weighted $10^{\text {th }}, 25^{\text {th }}$, $50^{\text {th }}, 75^{\text {th }}$, and $90^{\text {th }}$ percentiles of the realized sales growth rate distribution in the year leading up

\footnotetext{
${ }^{3}$ Specifically, $z_{i t} \equiv 0.5 e m p_{i, t-12}+0.5 E\left(e m p_{i, t+12}\right)$ and $z_{t} \equiv \sum_{i} z_{i t}$. See Davis and Haltiwanger (1999) on the excess reallocation formula and the choice of weights. In practice, we winsorize $z_{i t}$ at 500 . We also winsorize past and expected future employment growth rates (before adding them) at the $1^{\text {st }}$ and $99^{\text {th }}$ percentiles of the distribution of realized and expected employment growth rates, following Altig et al. (2020).

${ }^{4}$ For sales, we winsorize $z_{i t}$ at the $85^{\text {th }}$ percentile of its distribution in the pooled sample from September 2016 to April 2020, and we winsorize the sales growth rate values in the same manner as the employment growth rates.

${ }^{5}$ Barrero, Bloom, and Davis (forthcoming) document a COVID-induced jump in expected excess reallocation rates using firm-level forecasts at a 12-month horizon. Relative to their evidence, Figure 1 uses realized plus expected firm-level changes over 24-month intervals and data that extend through December 2020.
} 
to $t$. Then, in December 2020, the most recent survey month, we compute the average salesweighted growth rate forecast (looking one year ahead) among firms within plus or minus five percentiles in the realized growth rate distribution.

Figure 2 plots percentiles of the realized one-year sales growth rate distribution from September 2016 through December 2020, and it appends the average one-year-ahead growth rate forecasts by percentile for the period from December 2020 to December 2021. The figure makes several points. First, the COVID-19 shock dramatically increased the dispersion of realized firmlevel growth rates. Second, this increased dispersion mainly involved lower growth rates in the bottom part of the distribution (the $25^{\text {th }}$ and $10^{\text {th }}$ percentiles). Third, the growth rate distribution narrowed after May 2020 but remained highly dispersed at the end of 2020. Notably, realized twelve-month growth rates in December 2020 were minus 10 percent at the $25^{\text {th }}$ percentile and minus 28 percent at the $10^{\text {th }}$ percentile. Fourth, and perhaps most striking, percentile-specific forecasts in December 2020 imply a continuation of pandemic-related shifts in sales revenue across firms, not a reversal. This result is seen in the positive growth rate forecasts among firms at the $90^{\text {th }}$ and $75^{\text {th }}$ percentiles of the realized growth rate distribution and the lower to nil growth rate forecasts for firms at the $25^{\text {th }}$ and, especially, $10^{\text {th }}$ percentiles of the realized growth rate distribution. Although the forecasts imply a narrowing of the growth rate distribution, Figure 2 yields no evidence of a systematic reversal in firm-level fortunes during 2021 that would partly unwind the changes that took place in the twelve months leading up to December 2020.

Perhaps firms over extrapolate from their experiences during COVID, and that is what we capture in the final data point in Figure 2. Specifically, firms may be biased towards forecasting future sales developments that resemble recent past experience. Barrero (2020) finds evidence of over extrapolation in pre-pandemic SBU data, as do Gennaioli, Ma, and Shleifer (2016) based on 
separate survey evidence for publicly-traded firms. Only time will tell whether over extrapolation in the SBU data on firm-level expectations formed in December 2020 is driving the apparent absence of systematic reversal effects in Figure 2.

Figures 1 and 2 indicate that COVID-19 is a persistent reallocation shock in two senses: First, firm-level outcomes and forecasts continue to show high rates of (expected) reallocation. Second, firm-level forecasts as of December 2020 show no evidence of a systematic reversal in the pandemic-driven shifts in sales across firms. However, these two figures say little about the specific direction or nature of reallocative shifts across firms. To make some progress in this direction, we now consider how industry-level employment shifts relate to employee capacity to work from home. Barrero, Bloom, and Davis (2020) provide evidence and analysis that working from home will persist after the pandemic ends. So, it seems plausible that industry-level shifts associated with working from home will persist as well.

We use firm-level data from the SBU to compute the employment-weighted average of past plus expected future employment growth rates for fourteen broad industry groups. We consider two separate periods comprising months before and during the COVID-19 pandemic September 2016 to February 2020, and March to December 2020, respectively. We obtain estimates from Dingel and Neiman (2020b) for the fraction of workers in each industry that are able to work from home. They consider how easy it is to work from home in each occupation based on task requirements, and how many workers a given industry employs in each occupation.

Figure 3 shows that relative employment growth trends shifted towards industries with a high capacity of employees to work from home (WFH). We sort industries by the share of employees who can work from home. Employees in Leisure and Hospitality have little capacity to work from home, while those in Finance \& Insurance or Education have high capacity. The figure 
plots past plus expected future employment growth rates for each industry during the pre-COVID and COVID periods. To construct these measures, we first compute realized plus expected growth rates over 24-month intervals centered on the survey month, as before. We then aggregate over firms to the industry level using firm-level employment weights.

The figure shows that industry employment growth trends are essentially uncorrelated with WFH capacity in the pre-COVID period. In contrast, they are strongly positively correlated with WFH capacity during the COVID period. The cross-industry correlation between the realized plus expected employment growth rate and WFH capacity is -0.04 in the pre-COVID period and 0.71 in the COVID period. See Papanikolaou and Schmidt (2020) for complementary evidence based on the relationship between industry-level stock returns and WFH capacity.

In summary, Figures 1 to 3 provide evidence that COVID-19 is a persistent reallocation shock. Firm-level data on past plus expected future growth rates point to high and rising rates of excess job and (especially) sales reallocation since the pandemic struck. As of December 2020, firms also foresee a continuation of COVID-induced sales reallocation effects over the next one year, not a reversal. Firms growing the most during 2020 foresee stronger growth in 2021, and vice versa for those with the sharpest revenue drops in 2020. Finally, COVID has shifted relative employment growth trends in favor of industries with a high WFH capacity and away from those with low WHF capacity. Although we cannot measure it using our data, this effect almost certainly operates within our broad industry groups as well. Evidence in Barrero, Bloom and Davis (2020) that working from home will stick after the pandemic ends, coupled with differences in WFH capacity across firms and industries, is another reason to think that COVID-19 is a persistent reallocation shock. 
Figure 1: Excess Reallocation Rates Computed from Realized and Forecasted Firm-Level Growth Rates with One-Year Look-Back and Look-Ahead

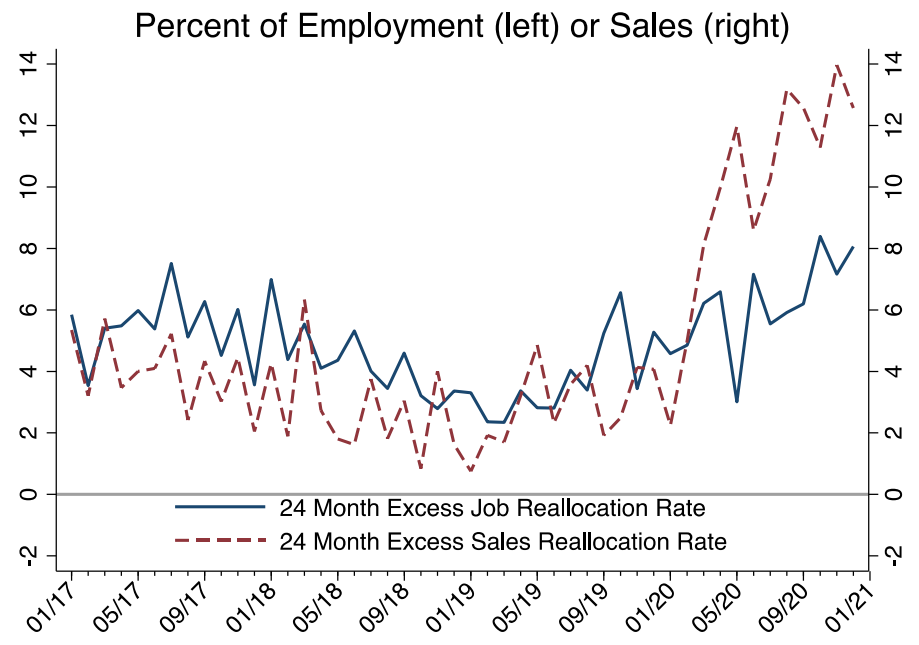

Source: Authors' calculations using data from the Survey of Business Uncertainty.

Notes: Data are monthly, and the sample period runs from January 2017 to December 2020, inclusive. See the text for an explanation of how we compute excess reallocation rates from firmlevel outcomes and forecasts.

Figure 2: Percentiles of Firm-Level Sales Growth Rates over the Preceding 12 Months and December 2020 Forecasts of Growth Rates over the Next 12 Months

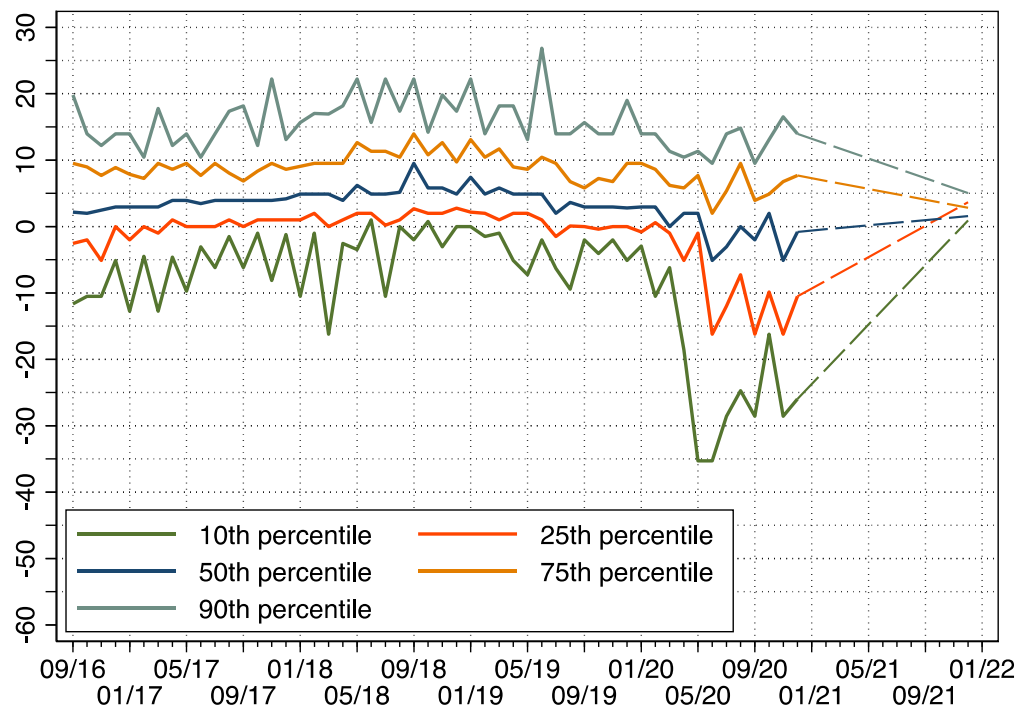

Source: Authors' calculations using data from the Survey of Business Uncertainty.

Notes: Data are monthly, and the sample runs from September 2016 to December 2020, inclusive. The last set of values (for December 2021) are averages of 12-month forecasts made in December 2020 by firms within plus or minus five percentiles of the indicated realized growth rate percentile. 
Figure 3: COVID-19 Shifted Employment Growth Rate Trends in Favor of Industries with a Greater Share of Jobs Suitable for Remote Work

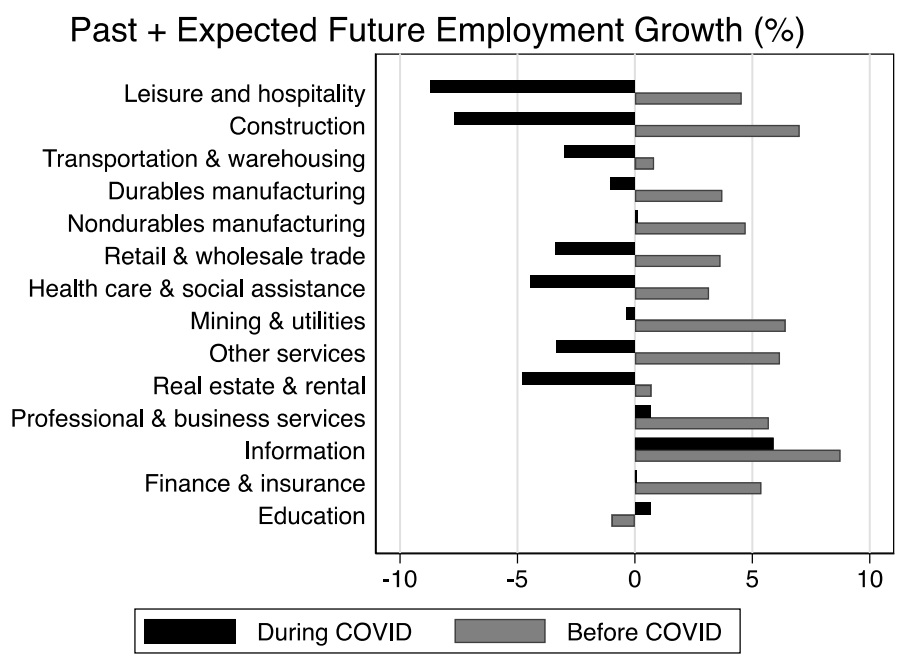

Source: Authors' calculations using data from the Survey of Business Uncertainty and measures of teleworkable employment shares at the industry level from Dingel and Neiman (2020b).

Notes: Industry groups are sorted by WFH capacity, from lowest to highest. For each industry group, we start with monthly observations on firm-level growth rates in the past 12 months and expected growth rates in the next 12 months. We then aggregate over firms to the industry level separately for the pre-COVID (9/2016-2/2020) and COVID (3/2020-12/2020) periods. Then we plot the average growth rate for each industry in the two periods.

\section{References}

Altig, David, Jose Maria Barrero, Nick Bloom, Steven J. Davis, Brent Meyer and Nick Parker, 2020. "Surveying Business Uncertainty” NBER Working Paper 25956. Revised, August 2020. Forthcoming, Journal of Econometrics.

Barrero, Jose Maria, 2020. "The Micro and Macro of Managerial Beliefs.” Working Paper, 9 April.

Barrero, Jose Maria, Nick Bloom, and Steven J. Davis, forthcoming. "COVID-19 Is Also a Reallocation Shock." Brookings Papers on Economic Activity.

Barrero, Jose Maria, Nick Bloom, and Steven J. Davis, 2020. "Why Working from Home Will Stick.” Working Paper, December 2020. 
Bender, Ruth and Matthew Dalton, 2020. "Coronavirus Pandemic Compels Historic Labor Shift: Outbreak Reshapes Job Market as Some Sectors Shut Down, Other See Demand Surge,” Wall Street Journal, 29 March 2020.

Bick, Alexander, Adam Blandin and Karel Mertens, 2020. "Work from Home after the COVID19 Outbreak,” Federal Reserve Bank of Dallas Working Paper 2017, June.

Brynjolfsson, Eric, John J. Horton, Adam Ozimek, Daniel Rock, Garima Sharma and Hong-Yi TuYe, 2020. "COVID-19 and Remote Work: An Early Look at U.S. Data," NBER Working Paper 27344.

Cajner, Tomaz, Leland D. Crane, Ryan A. Decker, John Grigsby, Adrian Hamins-Puertolas, Erik Hurst, Christopher Kurz and Aju Yildirmaz, 2020. "The U.S. Labor Market during the Beginning of the Pandemic Recession," June. Prepared for the Brookings Papers on Economic Activity.

Davis, Steven J. and John Haltiwanger, 1999. "Gross Job Flows," Handbook of Labor Economics, Volume 3B, Orley Ashenfelter and David Card, editors, Amsterdam: North-Holland.

Dingel, Jonathan I. and Brent Neiman, 2020. "How many jobs can be done at home?" Journal of Public Economics, 189, 104235.

Gennaioli, Nicola, Yueran Ma and Andrei Shleifer, 2016. "Expectations and Investment," NBER Macroeconomics Annual, 30, 379-431.

Guerrieri, Veronica, Guido Lorenzoni, Ludwig Straub and Ivan Werning, 2020. "Macroeconomic Implications of COVID-19: Can Negative Supply Shocks Cause Demand Shortages?" NBER Working Paper No. 26918.

Haltiwanger, John, 2020. “Applications for New Businesses Contract Sharply in Recent Weeks: A First Look at the Weekly Business Formation Statistics." Working Paper. April 2020. 
Mitchell, Josh, 2020. "Your Covid-19 Shopping Habits Are Changing What Jobs Are Available," Wall Street Journal, 4 December 2020.

Ozimek, Adam, 2020. “The Future of Remote Work,” SSRN Working Paper.

Papanikolaou, Dimitris and Lawrence D.W. Schmidt, 2020. "Working Remotely and the SupplySide Impact of COVID-19," NBER Working Paper No. 27330. 